\title{
CORRELATIONS BETWEEN AUXOLOGICAL INDICES AND THYROID VOLUME IN CHILDREN WITH STATURE DELAY IN ENDEMIC AND NON-ENDEMIC AREAS OF SIBIU COUNTY
}

\author{
IOANA-CODRUȚA LEBĂDĂ $\breve{~}^{1}$ \\ l "Lucian Blaga" University of Sibiu
}

Keywords: endemic area, goiter, thyroid volume

\begin{abstract}
Palpation of the thyroid gland, completed by its ultrasonographic examination, is an important method for assessing endocrine disorders caused by insufficient iodine intake. Hypothyroidism (through iodine deficiency) can be one of the main endocrine causes of poor mental and somatic development in children. The data obtained after palpation and ultrasonographic determination of thyroid volume in two groups of children (6-12 years) with small stature from different areas of Sibiu County, a submontane area (endemic) and a hilly area (non-endemic), show statistically significant differences between the values obtained for the two groups. Goiter was present in over half of the children living in the endemic area, a statistically significant percentage, higher than that obtained for the hilly area; thyroid volume values were statistically significantly higher compared to those of non-endemic area. Thyroid volume correlates positively and statistically significantly, both with the auxological indices of children (height and body mass), but especially with their age.
\end{abstract}

\section{INTRODUCTION}

Measuring the size and volume of the thyroid is an important method in diagnosing thyroid disorders caused by insufficient iodine intake, this can be done either by palpatory methods or by ultrasonographic techniques.(1) Thyroid ultrasound is a safe, accurate, and non-invasive method of measuring thyroid volume, which can be performed, without any contraindications, in children, regardless of age.(2)

The causes of small stature in children are varied, the most common being the constitutional delay in growth and installation of puberty but also familial small stature, as well as pathological causes, of which an important role is played by endocrine disorders. $(3,4)$ These are mainly represented by pituitary dysfunction that causes growth hormone $(\mathrm{GH})$ deficiency, thyroid gland failure (hypothyroidism), and Cushing's syndrome represented by an excess of glucocorticoids.(3)

Iodine is a necessary trace element in the human body, intervening in all stages of the synthesis of thyroid hormones, thyroxine (T4) and triiodothyronine (T3), hormones that play an extremely important role in tissue growth and development.(5) Deficiency of thyroid hormones from birth (congenital hypothyroidism) or childhood (juvenile hypothyroidism), decreases the rate of postnatal growth and influences skeletal development.(6)

\section{AIM}

We propose the clinical, palpatory, and ultrasonographic examination of two groups of children previously detected with small stature, residents of endemic and non-endemic areas in Sibiu County, Romania; and determining the correlations between auxological parameters and their thyroid volume.

\section{MATERIALS AND METHODS}

This study included 56 children aged between 6 and 12 years, detected with small stature, 32 of them being residents of localities situated in endemic areas, and 24 of them coming from localities situated in areas with an appropriate iodine intake.

It was performed, by the same examiner, the clinical exam of the thyroid gland by palpatory examination, the degree of goiter being determined using the classification proposed by the World Health Organization (WHO): grade 0 - thyroid that is not visible or palpable in the neck; grade 1 - the thyroid can be highlighted by palpation but without being visible in the anterior cervical region with the neck in a normal position; grade 2 - the thyroid is visible in the neck in normal position, and palpable.(7)

For thyroid ultrasonography, we used a Versana Premier Ultrasound from General Electric Healthcare with a linear probe with a frequency of 6-10 MHz. Thyroid volume (Tvol) was calculated according to the following formula proposed by Brunn et al. (8) where: the volume of each thyroid lobe $(\mathrm{mL})=$ anteroposterior diameter $(\mathrm{cm}) \times$ mediolateral diameter $(\mathrm{cm}) \times$ craniocaudal diameter $(\mathrm{cm}) \times 0.479$; and the total thyroid volume represents the sum of the volumes of both thyroid lobes (8.9). In all cases where the thyroid isthmus did not show one or more nodular formations, it was not taken into account for the determination of thyroid volume. The data obtained were compared with those proposed by Delange et al. (2) in 1997 under the WHO-recognized ThyroMobil project; but also with the new references published in 2004 (9) for children aged 6-12 years living in areas with an optimal iodine intake.

The data obtained were initially processed in the Excel program version 2016 , later we performed the statistical analysis using the program Minitab version 2018.

${ }^{1}$ Corresponding author: Ioana Codruța Lebadă, Str. Lucian Blaga, Nr.2A, Sibiu, România, E-mail:codruta.lebada@ulbsibiu.ro, Phone: +40269 436777 Article received on 03.10.2021 and accepted for publication on 02.12.2021 


\section{CLINICAL ASPECTS}

RESULTS

A total of 56 patients aged between 6 and 12 years were investigated, 24 of them (18 boys and 6 girls) come from non-endemic areas of Sibiu County (hill and plain areas), and 32 children ( 24 boys and 8 girls) are residents of localities situated in endemic regions (mountainous and submontane areas).

After clinical examination of the thyroid gland by palpation, we obtained a statistically significant higher percentage of the presence of goiter in children in the submontane area, with $59.38 \%$ (19 children) showing goiter grade I and $6.24 \%$ ( 2 children) with goiter grade II; compared to those in the hilly area where, in more than half of the children $(66.67 \%)$, the thyroid was not palpable (goiter grade 0) (table no. 1).

Table. no. 1. Classification of goiter following clinical examination in subjects from the two geographical areas

\begin{tabular}{|c|l|l|l|}
\hline $\begin{array}{c}\text { Degree of } \\
\text { goiter }\end{array}$ & $\begin{array}{c}\text { Non-endemic area } \\
\text { No. Subjects (\%) }\end{array}$ & $\begin{array}{c}\text { Endemic area } \\
\text { No. Subjects (\%) }\end{array}$ & p-value \\
\hline 0 & $16(66.67 \%)$ & $11(34.38 \%)$ & \multirow{2}{*}{$\mathbf{0 . 0 4 5}$} \\
\hline I & $8(33.33 \%)$ & $19(59.38 \%)$ & \\
\hline II & $0(0 \%)$ & $2(6.24 \%)$ & \\
\hline
\end{tabular}

Following the thyroid ultrasonography and subsequently the calculation of the thyroid volume, we represented in table number 2 the statistical parameters obtained for each group of children, as well as the p-values obtained after applying the corresponding statistical tests.

We aimed to establish the correlations between Tvol obtained according to sex, age, and anthropometric indices of the subjects included in the study, respectively to correlate Tvol with their height and body mass, represented in Figures 1 and 2. It was obtained the following Pearson correlation indices, with p-values $<0,0001$ in all analysed situations: between age and Tvol: in boys in the hilly area $r=0.901$; in boys in the submontane area $r=0.851$; in girls in the hilly area $r=0.931$; in girls in submontane area $\mathrm{r}=0.846$; between height and Tvol: in boys in the hilly area $r=0.891$; in boys in submontane area $r=$ 0.810 ; in girls in the hilly area $\mathrm{r}=0.809$; in girls in the submontane area $\mathrm{r}=0.788$; between body mass and Tvol: in boys in the hilly area $\mathrm{r}=0.894$, in boys in the submontane area $\mathrm{r}$ $=0.751$; in girls in the hilly area $\mathrm{r}=0.707$; in girls in the submontane area $r=0.602$

Figure. no. 1. Correlation between thyroid volume and height (submontane area/hilly area)

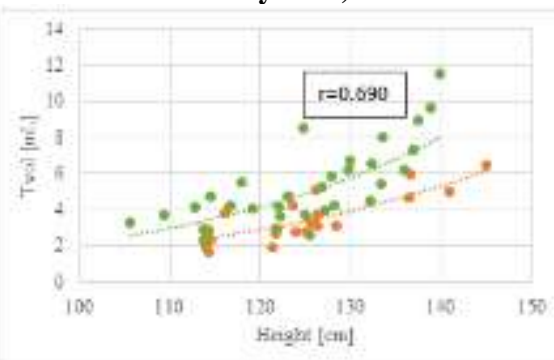

Figure. no. 2. Correlation between thyroid volume and body mass (submontane area/hilly area)

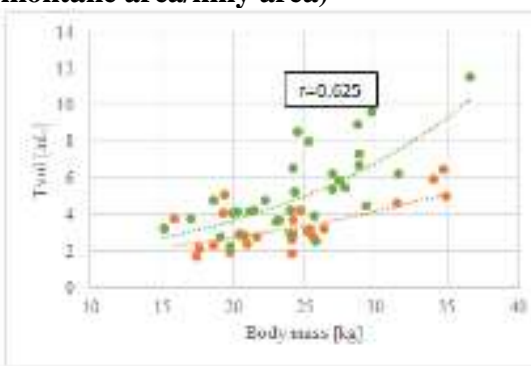

\section{DISCUSSIONS}

In 1997, WHO published references to thyroid volume in children in four European countries, by age and sex, standards that were revised due to subsequent studies conducted worldwide (United States, Switzerland, Malaysia), and which put highlights values of medians of thyroid volume significantly lower compared to European,(2,10-13) Thus, in 2004, Ziemmermann et al. published new international standards for thyroid volume obtained for children aged 6 to 12 years, residents of areas with a proven adequate iodine intake.(9) Compared to these new internationally accepted standards, the results obtained in our study do not differ statistically significantly for any of the studied age groups or sex, both for children from the submontane area (endemic) and for those coming from the hilly area (non-endemic).

Compared to the WHO references from 1997, we obtained statistically significant differences for the values calculated in children in the hilly area, at all ages and both sexes ( $p$-value $=0.009, p$-value $=0.007)$, but we recorded insignificant statistical differences for the values obtained in children in the submontane area $(\mathrm{p}$-value $=0.901, \mathrm{p}$-value $=0.495)$. This may be due to the persistence of iodine deficiency in that specific submontane region, which also translates into the presence of an increased percentage (over 50\%) of goiter grade I (59.38\%) and goiter grade II $(6.24 \%)$ goiter after palpation of the thyroid.

A study published in 2013, conducted in three mountain localities in Mureș County, revealed an increased prevalence $(51.1 \%)$ of goiter grade I and goiter grade II $(6.7 \%)$ in children aged between 8 and 14 years from those areas, results similar to those obtained in our study (14). High prevalences of goiter in children, following palpatory examination of the thyroid gland and staging according to the WHO classification, have been highlighted by multiple studies conducted internationally: from $39.9 \%$ in 2005 (15) to $36.6 \%$ in 2019 in Ethiopia (16), or $48.3 \%$ in 2012 in children in rural India.(17) Following the determination by ultrasound measurement, and calculation of thyroid volume in the children included in the study, we found statistically significant different values; higher in the children living in the mountain area than in those from the hilly area for the age groups 6-9 years $(\mathrm{p}$-value $=$ $0.025, \mathrm{p}$-value $=0.047, \mathrm{p}$-value $=0.044, \mathrm{p}$-value $=0.050)$

Table no. 2. Statistical parameters of thyroid volume obtained by thyroid ultrasonography of subjects assessed by age groups and by geographical areas

\begin{tabular}{|c|c|c|c|c|c|c|c|c|c|}
\hline \multirow[b]{2}{*}{$\begin{array}{l}\text { Age } \\
\text { [years] }\end{array}$} & \multicolumn{4}{|c|}{ Non-endemic area } & \multicolumn{4}{|c|}{ Endemic area } & \multirow[b]{2}{*}{$\begin{array}{l}\text { p- } \\
\text { value }\end{array}$} \\
\hline & $\begin{array}{l}\text { No. } \\
\text { subjects }\end{array}$ & $\mathrm{B} / \mathrm{F}$ ratio & $\begin{array}{l}\text { Median Tvol } \\
{[\mathrm{mL}]}\end{array}$ & $\begin{array}{l}\text { Min-Max } \\
{[\mathrm{mL}]}\end{array}$ & $\begin{array}{l}\text { No. } \\
\text { subjects }\end{array}$ & $\mathrm{B} / \mathrm{F}$ ratio & $\begin{array}{l}\text { Median Tvol } \\
{[\mathrm{mL}]}\end{array}$ & $\begin{array}{l}\text { Min-Max } \\
{[\mathrm{mL}]}\end{array}$ & \\
\hline 6 & 4 & $4 / 0$ & $2.26( \pm 0.40)$ & $1.94-2.88$ & 4 & $2 / 2$ & $3.49( \pm 0.59)$ & $2.77-4.15$ & 0.025 \\
\hline 7 & 6 & $3 / 3$ & $2.50( \pm 0.53)$ & $1.69-2.96$ & 6 & $3 / 3$ & $3.29( \pm 0.91)$ & $2.26-4.78$ & 0.047 \\
\hline 8 & 7 & $6 / 1$ & $3.26( \pm 0.55)$ & $2.78-4.24$ & 8 & $6 / 2$ & $4.21( \pm 0.93)$ & $2.56-5.48$ & 0.044 \\
\hline 9 & 2 & $1 / 1$ & $3.63( \pm 0.69)$ & $3.14-4.12$ & 4 & $4 / 0$ & $5.76( \pm 1.05)$ & $4.26-6.68$ & 0.050 \\
\hline 10 & 1 & $0 / 1$ & 5.12 & - & 5 & $4 / 1$ & $6.54( \pm 0.77)$ & $4.46-8.56$ & - \\
\hline 11 & 2 & $2 / 0$ & $5.28( \pm 0.93)$ & $4.62-5.94$ & 3 & $3 / 0$ & $7.34( \pm 1.35)$ & $6.24-8.92$ & 0.161 \\
\hline 12 & 2 & $2 / 0$ & $5.75( \pm 1.03)$ & $5.02-6.48$ & 2 & $2 / 0$ & $10.59( \pm 1.34)$ & $9.64-11.54$ & 0.154 \\
\hline
\end{tabular}

The p-value was calculated with $T$ student test

AMT, vol. 26, no. 4, 2021, p. 48 


\section{CLINICAL ASPECTS}

Values similar to those obtained in our study are those published in 2015, for a group of 422 children in Istanbul, Turkey, for the age groups 11-13, 8-10, and 5-7 years.(1) Another study, conducted in Poland and published in 2012, obtained values similar to those obtained in this study, in 642 children (aged 6-12 years), lower values compared to the 1997 references, but higher compared to the new standards adopted in 2004.(18)

The results obtained in this study demonstrate a positive correlation between thyroid volume and age $(\mathrm{r}=0.901$, $\mathrm{r}=0.851, \mathrm{r}=0.931, \mathrm{r}=0.846)$, height $(\mathrm{r}=0.891, \mathrm{r}=0.810, \mathrm{r}=$ $0.809, \mathrm{r}=0.788)$ and body mass $(\mathrm{r}=0.894, \mathrm{r}=0.751, \mathrm{r}=0.707$, $r=0.602$ ) of the evaluated children, similar to those obtained in the study in Turkey, the best correlations being established between thyroid volume and the age of the evaluated children.(1) The same positive correlations, statistically significant ( $\mathrm{p}$-value $<0.001$ ), between thyroid volume and age, respectively auxological indices (height, body weight) in schoolage children, have been demonstrated in many other studies conducted internationally, especially in endemic areas.(19,20)

\section{CONCLUSIONS}

Iodine deficiency currently remains a public health problem that can affect the somatic development of children living in endemic areas, and the results of this study show the presence of goiter in more than half of school-children assessed in the mountainous area (endemic), a significant percentage statistically higher than that obtained in school-children in the hilly (non-endemic) area. Also, the thyroid volume, calculated and compared with the international standards established for the age groups 6-9 years, has statistically significantly higher values in children in the submontane area compared to those in the hilly area. The values of thyroid volume correlate positively, and statistically significantly, both with age and with auxological parameters represented by the height and body mass of the evaluated children.

\section{REFERENCES}

1. Aydıner Ö, Karakoç Aydıner E, Akpınar İ, Turan S, Bereket A. Normative Data of Thyroid VolumeUltrasonographic Evaluation of 422 Subjects Aged 0-55 Years. J Clin Res Pediatr Endocrinol. 2015;7(2):98-101.

2. Delange F, Benker G, Caron P, et al. Thyroid volume and urinary iodine in European schoolchildren: standardization of values for assessment of iodine deficiency. Eur J Endocrinol. 1997;136:180-187.

3. Abdulrazak A. Evaluation of the Child with Short Stature. Middle East Journal of Family Medicine. 2017;2:27-32.

4. Saengkaew T, McNeil E, Jaruratanasirikul S. Etiologies of short stature in a pediatric endocrine clinic in Southern Thailand. J Pediatr Endocrinol Metab. 2017;30:1265-1270.

5. Bougma $\mathrm{K}$, Aboud FE, Harding $\mathrm{KB}$, et al. Iodine and mental development of children 5 years old and under: a systematic review and meta-analysis. Nutrients. 2013;5(4):1384-1416.

6. Gardner D, Shoback D. Greenspan Basic and Clinical Endocrinology. 9th Edition McGraw Hill Lange; 2011.

7. WHO/ICCIDD/UNICEF. Assessment of the iodine deficiency disorders and monitoring their elimination. Geneva: WHO; 2001.

8. Brunn J, Block U, Ruf G, et al. Volumetric analysis of thyroid lobes by real-time ultrasound. J Dtsch Med Wochenschr. 1981;106:1338-1340.

9. Zimmermann MB, Sonya Y Hess, Molinari L, et al. New references values for thyroid volume by ultrasound in iodine-sufficient schoolchildren: a World Health Organization/Nutrition for Health and Development Iodine
Deficiency Study Group Report. Am J Clin Nutr. 2004;79:231-237.

10. Foo LC, Zulfiqar A, Nafikudin M, et al. Local versus WHO/ International Council for the Control of Iodine Deficiency Disorders-recommended thyroid volume reference in the assessment of iodine deficiency disorders. Eur J Endocrinol. 1999;140:491-497.

11. Hess SY, Zimmermann MB. Thyroid volumes in a national sample of iodine-sufficient Swiss school children: comparison to the World Health Organization/International Council for the Control of Iodine Deficiency Disorders normative thyroid volume criteria. Eur J Endocrinol. 2000;142:599-603.

12. WHO/ICCIDD. Recommended normative values for thyroid volume in children aged 6-15 years. Bulletin of the World Health Organization. 1997;75:95-97.

13. Xu F, Sullivan K, Houston R, et all. Thyroid volumes in US and Bangladeshi schoolchildren: comparison with European schoolchildren. Eur J Endocrinol. 1999;140:498504

14. Kun IZ, Zsuzsanna Szanto, Balazs J, et al. Detection of Iodine Deficiency Disorders (Goiter and Hypothyroidism) in School-Children Living in Endemic Mountainous Regions, After the Implementation of Universal Salt Iodization. Hot Topics in Endocrine and Endocrine-Related Diseases. 2013;4:101-128.

15. Abuye C, Berhane $\mathrm{Y}$, Akalu G, et al. Prevalence of goiter in children 6 to 12 years of age in Ethiopia. Food Nutr Bull. 2007;28:391-398.

16. Bekele A, Adilo TM. Prevalence of goiter and its associated factors among primary school children in Chole District, Arsi Zone, Ethiopia: a cross-sectional study. BMC Nutr. 2019;5:2-10.

17. Pandit MI, Raja W, Hussain R, et al. Prevalence of Goiter in School-Age Children (6-12 years) in a Rural District (Bandipura) of Kashmir Valley. International Journal of Science and Research (IJSR). 2015;4:2223-2225.

18. Szybiński Z, Trofimiuk-Müldner M, Buziak-Bereza M, et al. Reference values for thyroid volume established by ultrasound in Polish schoolchildren. Endokrynol Pol. 2012;63:104-109.

19. Semiz S, Senol U, Bircan, Gümüşlü S, Bilmen S, Bircan I. Correlation between age, body size and thyroid volume in an endemic area. J Endocrinol Invest. 2001;24(8):559-63.

20. Bu KK, et al. Determination of Thyroid Volume by Ultrasonography among Schoolchildren in Philippines. International Journal of Endocrinology. 2012;2012:1-7. 